American Journal of Economics and Business Administration 3 (4): 623-635, 2011

ISSN 1945-5488

(C) 2011 Science Publications

\title{
Price-Value Potential for Near-Perfectly Competitive Markets
}

\author{
Sergey K. Aityan \\ Lincoln University, 401 15th Street, Oakland, CA 94612, USA
}

\begin{abstract}
This study introduces price-value potential to be used instead of price for market analysis by analogy with free energy or thermodynamic potential in physics. A conservation principle is proposed for price-value potential. It is shown that price-value potential provides a constructive way for market analysis by identifying variation of equilibrium prices and quantities for different products in market equilibrium. A perturbation theory for a group of products with small differentiations on near-perfectly competitive markets was developed for illustration of the approach. The concept of price-value potential is illustrated in a simple example of a near-perfectly competitive market. It is shown that the equilibrium prices and quantities for products differ due to product differentiation that makes such an approach a constructive enhancement to the classical model of perfect competition.
\end{abstract}

Key words: Market equilibrium, differentiation, perfect competition, value, price-value, market modeling, market free energy

\section{INTRODUCTION}

The price-quantity approach for demand and supply constitutes a fundamental cornerstone of economics. This approach has been broadly utilized for market analysis and modeling. Market equilibrium occurs at a price when demand equals supply.

A deficiency of the price-quantity approach is that it has certain flaws in market equilibrium analysis. Such a deficiency can be illustrated by its inability to define aggregate market equilibrium for a group of products with small differentiations in a near-perfectly competitive market. The term near-perfectly competitive market is introduced in this study and refers to a market with all characteristics similar to classical perfect competition (Pindyck and Rubinfeld, 2009; Paul and Nordhaus, 2009) except product homogeneity. Products in the near-perfectly competitive market may show small differentiation which is a more realistic assumption for a real-world market. In contrast to monopolistic competition, there are no brands differences, no entry or exit barriers and buyers make their buying decisions based only on price slightly adjusted to a small product differentiation. The model of perfect competition is an abstract model that never exists in the real world; in any real-world market that is close to the model of perfect competition some degree of product differentiation inevitably occurs.

The model of perfect competition leads to a conclusion that firms in a perfectly competitive market are price takers because the market consists of a large number of small sellers and buyers, so none of the participants are able to impact the market equilibrium. "Perfect Competition (PC), despite its abstract nature, is central to the literature on shadow prices and remains an important benchmark in economic policy analysis" (Thampapillai, 2010). In a perfectly competitive market, suppliers have to sell and buyers have to buy at the equilibrium market price regardless of the quantities any individual seller and buyer sell and buy. Products in a perfectly competitive market are assumed to be identical, which is not true in the real world because some differentiation-no matter how small-always takes place. Such differentiation leads to the appropriate variation in pricing. Thus even though the model of perfect competition is very concise and clear, it remains an abstract model and cannot be applied in the real world to suggest prices for products with small differentiations in a near-perfectly competitive market.

It was shown that for a finite number of commodities, perfect competition is a good approximation for describing market equilibrium for a market of small firms with free market entry (Novshek, 1980; Novshek and Sonnenschein, 2012; 1980). MasColell (1975) showed that a market of insignificantly small companies with slightly differentiated but almost perfectly substitutable products produced with very similar technologies is very close to perfect competition. Hart (1980) and Fradera (1986) conducted a detailed analysis of econometric models for the market of a differentiated products showing the conditions when such a market converges to a perfectly competitive market. Hart (1979) analyzed the evolution of monopolistic equilibrium as firms become insignificantly small relative to the market. Product 
diversity and its impact on monopolistically competitive market were analyzed by Dixit and Stiglitz (1977). Their analysis lead to a quite intensive discussion and additional comments (Dixit and Stiglitz, 1993). However monopolistic competition and perfect competition are quite different models which are applied to different markets.

The main purpose of this study is to introduce a new concept of price-value potential instead of classical approach based on price for demand and supply analysis and modeling of real-world markets. This study suggests price to be part of price-value which is a more general factor responsible for market equilibrium similarly to free energy or thermodynamic potentials in physics which are used to describe system equilibrium instead of just energy. A near-perfectly competitive market with products showing small differentiation is used in this study for the illustrative purpose only to demonstrate the deficiency of the traditional pricequantity approach and to show the advantages of the suggested price-value potential approach introduced for demand and supply market analysis and modeling.

Demand and supply in the traditional economic theory: In traditional economic theory, demand and supply are presented in terms of quantity and price. Demand is defined as the quantity of a particular product that consumers are willing to buy at a given price and supply is the quantity of that product that suppliers are willing to produce at a given price (Pindyck and Rubinfeld, 2009; Paul and Nordhaus, 2009). For the sake of generality, the term product refers to both goods and services. Assuming monotonous dependency of demand and supply curves, one can also define demand and supply as the inverse function of price on quantity.

This approach constitutes the major foundation for a variety of economic theories and market analysis. It would be no exaggeration to say that demand and supply drive markets.

\section{Classical and modern views at perfect competition:} Price takers in perfect competition: A perfectly competitive firm must sell at market price $\mathrm{P}_{0}$, no higher, no lower. If the firm sells at a price greater than the market price then the buyers buy from its competitors. If the firm sells at a lower price then the firm just loses its possible profit. This is one of the most interesting conclusions of the model of a perfectly competitive market.

Modern understanding of perfect competition: The model of perfect competition is widely applied in economic theory. Though a perfectly competitive market is a theoretical abstraction that never occurred in the real world, some markets can converge to perfectly competitive markets. Shneyerov and Wong (2010) theoretically studied the steady state market and its conversion to perfect competition as a bargain process of incoming buyers and sellers under private information. Cournot equilibrium with an infinite number of competitors tends to become perfect competition. However, stability of the equilibrium in such a conversion was questioned and analyzed by Puu (2008).

The model of perfect competition leads to a belief that such a market represents basically no competition at all (Petersen and Lewis, 1999) because all its participants play a quite passive role and thus no innovation is possible under such conditions. Despite this strong belief, however, innovations can actively take place under near-perfectly competitive conditions (Boldrin and Levine, 2008) that may result in product differentiation.

Bradley (2010) argues that the modern model of perfect competition differs from Smith's perfect liberty in a number of important aspects including the role of active competition among firms and the role of the entrepreneur. Though the model of perfect competition is based on "complete knowledge," neoclassical perfect competition implies limited knowledge that leads to the conclusion that brokers can exist in perfect competition (Stigler, 1995). Briglauer and Reichinger (2008) studied the chances of contestability in communications and concluded that the theory of contestable markets is an essential generalization of the neoclassical theory of perfect competition. This conclusion implies that the large number of price-taking firms is no longer a condition for an efficient market due to heterogeneity in business enterprises. Classical perfect competition implies a complete homogeneity of the market that never occurs in the real world and for this reason market information is always heterogeneous and even asymmetric (Sun and Yannelis, 2007).

Found that "mapping between value creation and value capture is moderated by industry-level factors and that firm heterogeneity depends on both, features of the resource development process and on features of the industry". McAfee and Velde (2008) analyzed pricing behavior and found out that elements of monopoly pricing may occur even in a perfectly competitive market environment.

In the application of the model of perfect competition to inventory management, Mishra and Mishra (2008) analyzed and optimized a unit price of the inventory for the EOQ (The term product refers to both goods and services) (EOQ stands for "economic order quantity" and is referred to the amount of orders 
that minimizes total variable costs required to order and hold inventory) model under perfect competition by using revenue and marginal cost as parameters for optimization.

Product differentiation and perfect competition: Though perfect competition assumes homogeneous products, the participating firms may produce different varieties of products. Such differentiations may impact the firm's way of doing business and its performance.

Challenges of the model of perfect competition in the real world: There are many markets in the real world that are quite close to the model of perfect competition but nevertheless their products show some differentiation and for this reason the most fundamental conclusions derived from the classical model of perfect competition fail in practical applications.

According to the model of perfect competition, all sellers are selling identical products and all sellers and buyers are too small to impact market equilibrium. In other words, there is no differentiation in a perfectly competitive market at all. If a seller sells at a price higher than the market equilibrium price, no buyers will buy from that seller. On the other hand, if a seller sells at a price lower than the market equilibrium price, he will definitely be able to sell the product but will get less revenue than in the case of selling at market price, which makes no sense.

"The primary critique of perfect competition as a positive model is that it is so unrealistic as to be misleading" (Block et al., 2002). Though perfect competition is an extreme model that does not match any market in the real world, some markets are quite close to it. For example, strawberries selling at a farmer's market is almost perfectly competitive. Does it mean that all sellers must sell their strawberries at the same price regardless of the taste, size and look of the strawberries? It is quite obvious that such advice cannot be given to the real-world sellers on a strawberry market. Some strawberries are better and are sold at a higher price while some are not as good and are sold at a lower price. This fact brings up a question of whether the model of perfect competition can find any application in the real world given that no market is absolutely perfectly competitive. If this is the case, then the value of this model becomes quite doubtful because some differences in products always take place in the real world. Then a legitimate question arises: how can one apply the model of perfect competition to a real world market if it is close to perfect competition but not quite perfect?

A similar concern could be extended to many other market models too. Is there any way to enhance the economic theory to bring it beyond the theoretical view in a real-world market and to provide reasonable recommendations to market participants?
Money as market energy: The role money plays in the market is similar to the role of energy in physics. Energy is associated with the work a system can perform, so is money. However, in physics there are other parameters such as entropy, temperature, pressure, volume, etc. that contribute to the potential work a system can perform. Similarly, in economy price (money) acts like energy but other parameters may impact supply and demand equilibrium.

Price, money and differentiation markups: Consider a perfectly competitive market of product $\mathrm{A}$ with market equilibrium price $\mathrm{P}_{0}^{\mathrm{A}}$ and equilibrium quantity $\mathrm{Q}_{0}^{\mathrm{A}}$. According to the model of perfect competition, every seller in such a market is a price taker and has to sell for $\mathrm{P}_{0}^{\mathrm{A}}$.

Product differentiation: Product A consists of a set of features $\mathrm{F}^{\mathrm{A}}=\left(\mathrm{f}_{1}^{\mathrm{A}}, \mathrm{f}_{2}^{\mathrm{A}}, \ldots, \mathrm{f}_{\mathrm{K}}^{\mathrm{A}}\right)$ where $\mathrm{K}$ is the total number of features, $1 \leq \mathrm{k} \leq \mathrm{K}$. Assume there is another product, $\mathrm{B}$, which is a modification of product $\mathrm{A}$ with some differentiation. The total differentiation consists of a set of partial differentiations $\theta_{\mathrm{k}}^{\mathrm{AB}}$ of each feature $\mathrm{f}_{\mathrm{k}}^{\mathrm{A}}$ :

$\theta_{\mathrm{k}}^{\mathrm{AB}}=\frac{\mathrm{f}_{\mathrm{k}}^{\mathrm{B}}-\mathrm{f}_{\mathrm{k}}^{\mathrm{A}}}{\mathrm{f}_{\mathrm{k}}^{\mathrm{A}}}=\frac{\Delta \mathrm{f}_{\mathrm{k}}^{\mathrm{AB}}}{\mathrm{f}_{\mathrm{k}}^{\mathrm{A}}}$

According to Eq. 1 partial product differentiation $\theta_{\mathrm{k}}^{\mathrm{AB}}$ can be measured in percents of deviation relative to a reference product feature component $f_{k}^{A}$ regardless of the units in which the features are measured. Features and their differentiation can be measured objectively or subjectively. A condition for small differentiation between $\mathrm{A}$ and $\mathrm{B}$ can be expressed as Eq. 2:

$\left|\theta_{\mathrm{k}}^{\mathrm{AB}}\right| \ll<1 \quad$ for all $\mathrm{k}=1,2,, \ldots, \mathrm{K}$

The total differentiation $\Theta^{\mathrm{AB}}=\left(\theta_{1}^{\mathrm{AB}}, \theta_{2}^{\mathrm{AB}}, \cdots, \theta_{\mathrm{K}}^{\mathrm{AB}}\right)$ is a vector of partial differentiations $\theta_{\mathrm{k}}^{\mathrm{AB}}$ of each feature component.

Price markup for differentiation: A product differentiation results in a positive or negative market markup for product $B$ relative to product $A$. With differentiation $\Theta^{\mathrm{AB}}$ consumers are willing to pay an additional price $\Delta \mathrm{P}_{\mathrm{D}}^{\mathrm{AB}}$ per unit of product $\mathrm{B}$ and suppliers are willing to produce the same quantity of product $\mathrm{B}$ as product $\mathrm{A}$ with a price markup $\Delta \mathrm{P}_{\mathrm{S}}^{\mathrm{AB}}$ per unit as shown in Eq. 3. With small differentiations, the price markups are: 


$$
\begin{aligned}
& \Delta \mathrm{P}_{\mathrm{D}}^{\mathrm{AB}}=\mathrm{C}_{\mathrm{D}} \Theta^{\mathrm{AB}}=\sum_{\mathrm{k}=1}^{\mathrm{K}} \mathrm{c}_{\mathrm{D}}^{\mathrm{k}} \theta_{\mathrm{k}}^{\mathrm{AB}} \\
& \Delta \mathrm{P}_{\mathrm{S}}^{\mathrm{AB}}=\mathrm{C}_{\mathrm{S}} \Theta^{\mathrm{AB}}=\sum_{\mathrm{k}=1}^{\mathrm{K}} \mathrm{c}_{\mathrm{S}}^{\mathrm{k}} \theta_{\mathrm{k}}^{\mathrm{AB}}
\end{aligned}
$$

where, $c_{D}^{k}$ is the additional price markup rate consumers are willing to pay per one percent of differentiation of feature component $f_{k}^{A}, c_{s}^{k}$ is the price markup rate for which suppliers are willing to produce the same quantity of the product with one percent differentiation, so $\quad \mathrm{C}_{\mathrm{D}}=\left(\mathrm{c}_{\mathrm{D}}^{1}, \mathrm{c}_{\mathrm{D}}^{\mathrm{k}}, \cdots, \mathrm{c}_{\mathrm{D}}^{\mathrm{K}}\right)$ and $\mathrm{C}_{\mathrm{S}}=\left(\mathrm{c}_{\mathrm{S}}^{1}, \mathrm{c}_{\mathrm{S}}^{\mathrm{k}}, \cdots, \mathrm{c}_{\mathrm{S}}^{\mathrm{K}}\right)$ are the consumer and supplier markup rate vectors appropriately. $\Delta \mathrm{P}_{\mathrm{D}}^{\mathrm{AB}}$ and $\Delta \mathrm{P}_{\mathrm{S}}^{\mathrm{AB}}$ are the total price markups, $\Delta \mathrm{P}_{\mathrm{Dk}}^{\mathrm{AB}}$ and $\Delta \mathrm{P}_{\mathrm{Sk}}^{\mathrm{AB}}$ are the price markups on partial differentiation $\theta_{\mathrm{k}}^{\mathrm{AB}}$ of feature $\mathrm{f}_{\mathrm{k}}^{\mathrm{A}}$ and $\mathrm{c}_{\mathrm{D}}^{\mathrm{k}}$ and $\mathrm{c}_{\mathrm{S}}^{\mathrm{k}}$ are the partial price markup rates that represent a price markup per one percent of differentiation. Note that consumer and supplier markup rates $\mathrm{C}_{\mathrm{D}}^{\mathrm{AB}}$ and $\mathrm{C}_{\mathrm{S}}^{\mathrm{AB}}$ can generally be unequal to each other. The consumer markup rate $C_{D}^{A B}$ shows how much consumers value the differentiation and reflects also a perceptional aspect of getting a differentiated product. For example, consumers would pay a higher price for clothing simply because they like the design better.

Consumer and supplier price markups $\Delta \mathrm{P}_{\mathrm{D}}^{\mathrm{AB}}$ and $\Delta \mathrm{P}_{\mathrm{S}}^{\mathrm{AB}}$ obey the transitivity rule in linear approximation with small differentiations, i.e. Eq. 4:

$$
\begin{aligned}
& \Delta \mathrm{P}_{\mathrm{D}}^{\mathrm{AB}}=\Delta \mathrm{P}_{\mathrm{D}}^{\mathrm{AM}}+\Delta \mathrm{P}_{\mathrm{D}}^{\mathrm{MB}}=\mathrm{C}_{\mathrm{D}} \\
& \left(\Theta^{\mathrm{AM}}+\Theta^{\mathrm{MB}}\right)=\sum_{\mathrm{k}=1}^{\mathrm{K}} \mathrm{c}_{\mathrm{D}}^{\mathrm{k}}\left(\theta_{\mathrm{k}}^{\mathrm{AM}}+\theta_{\mathrm{k}}^{\mathrm{MB}}\right) \\
& \Delta \mathrm{P}_{\mathrm{S}}^{\mathrm{AB}}=\Delta \mathrm{P}_{\mathrm{S}}^{\mathrm{AM}}+\Delta \mathrm{P}_{\mathrm{S}}^{\mathrm{MB}}=\mathrm{C}_{\mathrm{S}} \\
& \left(\Theta^{\mathrm{AM}}+\Theta^{\mathrm{MB}}\right)=\sum_{\mathrm{k}=1}^{\mathrm{K}} \mathrm{c}_{\mathrm{S}}^{\mathrm{k}}\left(\theta_{\mathrm{k}}^{\mathrm{AM}}+\theta_{\mathrm{k}}^{\mathrm{MB}}\right)
\end{aligned}
$$

A difference between consumer and supplier markups indicates a degree of market adding value rate of the differentiation Eq. 5:

$\mu_{\mathrm{AB}}=\frac{\mathrm{C}_{\mathrm{D}}^{\mathrm{AB}}-\mathrm{C}_{\mathrm{S}}^{\mathrm{AB}}}{\mathrm{C}_{\mathrm{S}}^{\mathrm{AB}}}$

Which will be referred to as market excitement. This parameter shows a degree of consumer valuation of the differentiation between products $A$ and B. If $\mu>0$, consumers appreciate the differentiation and are willing to pay more than the cost of the differentiation for it, if $\mu<0$ consumers do not appreciate the differentiation and are not willing to pay even the extra cost. If $\mu=0$ consumers are neutral to the differentiation and are willing to pay just to cover the cost of this differentiation.

Shift and sag of the demand and shift of supply curves with differentiation: Differentiation $\Theta^{\mathrm{AB}}$ leads to a horizontal shift of the demand and supply curves $\mathrm{Q}_{\mathrm{D}}^{\mathrm{A}}(\mathrm{P}) \quad$ and $\quad \mathrm{Q}_{\mathrm{S}}^{\mathrm{A}}(\mathrm{P})$ by $\Delta \mathrm{P}_{\mathrm{D}}^{\mathrm{AB}}=\mathrm{C}_{\mathrm{D}}^{\mathrm{AB}} \Theta^{\mathrm{AB}} \quad$ and $\Delta \mathrm{P}_{\mathrm{S}}^{\mathrm{AB}}=\mathrm{C}_{\mathrm{S}}^{\mathrm{AB}} \Theta^{\mathrm{AB}}$ correspondingly. As soon as consumers are willing to pay extra $\Delta \mathrm{P}_{\mathrm{D}}^{\mathrm{AB}}$ for product $\mathrm{B}$ compared to product $\mathrm{A}$, it would be natural to assume that the demand curve for product $\mathrm{B}$ also sags by $\Delta \mathrm{Q}_{\mathrm{D}}^{\mathrm{AB}}$. The demand curve sags because consumers, though willing to pay more for a unit of the differentiated product $B$, will buy less units of product $B$ than product $A$ due to the price difference $\Delta \mathrm{P}_{\mathrm{D}}^{\mathrm{AB}}$ per unit. Most likely the demand sag $\Delta Q_{D}^{A B}$ is a function of the demand shift $\Delta \mathrm{P}_{\mathrm{D}}^{\mathrm{AB}}$. Generally $\Delta \mathrm{Q}_{\mathrm{D}}^{\mathrm{AB}}\left(\Delta \mathrm{P}_{\mathrm{D}}^{\mathrm{AB}}\right)$ may be a nonlinear function of $\Delta \mathrm{P}_{\mathrm{D}}^{\mathrm{AB}}$, however, with small differentiation it is reasonable to assume a linear dependence as Eq. 6:

$\Delta \mathrm{Q}_{\mathrm{D}}^{\mathrm{AB}}=\lambda \Delta \mathrm{P}_{\mathrm{D}}^{\mathrm{AB}}=\lambda \mathrm{C}_{\mathrm{D}}^{\mathrm{AB}} \Theta^{\mathrm{AB}}$

Thus the demand and supply curves $\mathrm{Q}_{\mathrm{D}}^{\mathrm{A}}(\mathrm{P})$ and $\mathrm{Q}_{\mathrm{S}}^{\mathrm{A}}(\mathrm{P})$ for product $\mathrm{A}$ transform to the demand and supply curves $\mathrm{Q}_{\mathrm{D}}^{\mathrm{B}}(\mathrm{P})$ and $\mathrm{Q}_{\mathrm{S}}^{\mathrm{B}}(\mathrm{P})$ for product $\mathrm{B}$ as shown in Eq. 7 and Fig. 1:

$$
\begin{aligned}
& Q_{D}^{B}(P)=Q_{D}^{A}\left(P-C_{D}^{A B} \Theta^{A B}\right)-\lambda C_{D}^{A B} \Theta^{A B} \\
& Q_{S}^{B}(P)=Q_{S}^{A}\left(P-C_{S}^{A B} \Theta^{A B}\right)
\end{aligned}
$$

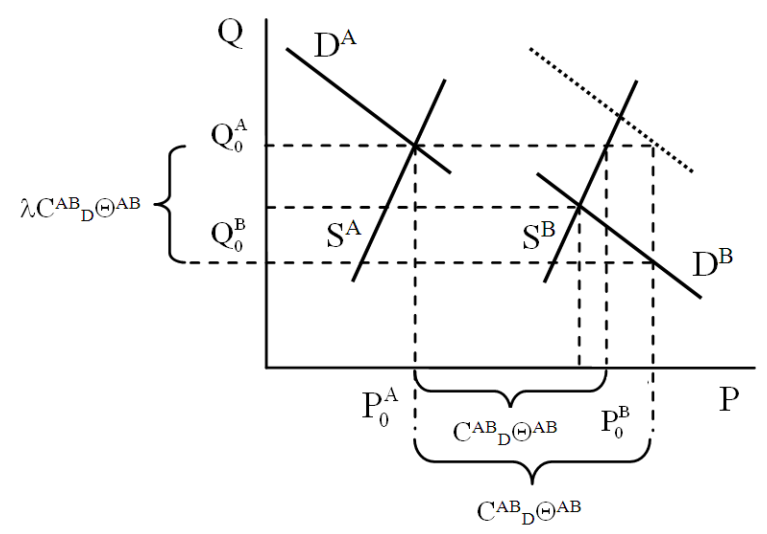

Fig. 1: Horizontal shift and sag of the supply and demand curves due to small product differentiation 
Note that the price markups and sag described above are not equal to the price markup in market equilibrium for product B but represent only the demand and supply curves shifts and demand curve sag as shown in Fig. 1. The skew of the demand and supply curves due to differentiation $\Theta^{\mathrm{AB}}$ is of second order by $\Theta^{\mathrm{AB}}$ and for this reason can be ignored in the linear approximation.

\section{Market equlibrium with differentiation:}

Market equilibrium for two products with small differentiation: As it becomes evident from Fig. 1, the shift of the market equilibrium point $\left(\mathrm{P}_{0}^{\mathrm{B}}, \mathrm{Q}_{0}^{\mathrm{B}}\right)$ for product $B$ from the equilibrium point $\left(\mathrm{P}_{0}^{\mathrm{A}}, \mathrm{Q}_{0}^{\mathrm{A}}\right)$ for product $\mathrm{A}$ is in general different from either the shift or sag of the demand curve or the shift of the supply curve. The demand and supply curves for product $\mathrm{A}$ in a vicinity of the equilibrium point can be written as Eq. 8 and 9:

$$
\begin{aligned}
& \mathrm{Q}_{\mathrm{D}}^{\mathrm{A}}=\mathrm{Q}_{0}^{\mathrm{A}}-\tau_{\mathrm{D}}^{\mathrm{A}}\left(\mathrm{P}-\mathrm{P}_{0}^{\mathrm{A}}\right) \\
& \mathrm{Q}_{\mathrm{S}}^{\mathrm{A}}=\mathrm{Q}_{0}^{\mathrm{A}}+\tau_{\mathrm{S}}^{\mathrm{A}}\left(\mathrm{P}-\mathrm{P}_{0}^{\mathrm{A}}\right)
\end{aligned}
$$

Where:

$$
\tau_{\mathrm{D}}^{\mathrm{A}}=-\left.\frac{\mathrm{dQ}_{\mathrm{D}}^{\mathrm{A}}}{\mathrm{dP}}\right|_{0} ^{\mathrm{A}} \quad \text { and } \quad \tau_{\mathrm{S}}^{\mathrm{A}}=\left.\frac{\mathrm{dQ_{ \textrm {S } } ^ { \mathrm { A } }}}{\mathrm{dP}}\right|_{0} ^{\mathrm{A}}
$$

Sign $\left.\right|_{0} ^{\mathrm{A}}$ denotes that the function on the left hand side of it is taken at $\mathrm{P}=\mathrm{P}_{0}^{\mathrm{A}}$. Note that typically $\frac{\mathrm{dQ}_{\mathrm{D}}^{\mathrm{A}}}{\mathrm{dP}}<0$ and $\frac{\mathrm{dQ}_{\mathrm{S}}^{\mathrm{A}}}{\mathrm{dP}}>0$ hence both $\tau_{\mathrm{D}}^{\mathrm{A}}>0$ and $\tau_{\mathrm{s}}^{\mathrm{A}}>0$. Note that in some quite exotic cases $\tau_{\mathrm{D}}^{\mathrm{A}}$ may be negative.

According to Eq. 7 and 8 the demand and supply lines for product B in a vicinity of the equilibrium are:

$$
\begin{aligned}
& Q_{D}^{B}=Q_{D}^{A}-\tau_{D}^{B}\left(P-P_{0}^{A}-C_{D}^{A B} \Theta^{A B}\right)-\lambda C_{D}^{A B} \Theta^{A B} \\
& Q_{S}^{B}=Q_{S}^{A}+\tau_{S}^{B}\left(P-P_{0}^{A}-C_{S}^{A B} \Theta^{A B}\right)
\end{aligned}
$$

where parameters Eq. 11:

$$
\begin{aligned}
& \tau_{D}^{\mathrm{B}}=\tau_{\mathrm{D}}^{\mathrm{A}}+\frac{\mathrm{d} \tau_{\mathrm{D}}^{\mathrm{A}}}{\mathrm{dz}} \Theta^{\mathrm{Ab}} \\
& \tau_{\mathrm{S}}^{\mathrm{B}}=\tau_{\mathrm{S}}^{\mathrm{A}}+\frac{\mathrm{d} \tau_{\mathrm{s}}^{\mathrm{A}}}{\mathrm{dz}} \Theta^{\mathrm{Ab}}
\end{aligned}
$$

In the equilibrium for product B Eq. 12:

$$
\mathrm{Q}_{\mathrm{D}}^{\mathrm{B}}\left(\mathrm{P}_{0}^{\mathrm{B}}\right)=\mathrm{Q}_{\mathrm{S}}^{\mathrm{B}}\left(\mathrm{P}_{0}^{\mathrm{B}}\right)=\mathrm{Q}_{0}^{\mathrm{B}} \text { and } \mathrm{P}=\mathrm{P}_{0}^{\mathrm{B}}
$$

Taking into account that $\mathrm{P}_{0}^{\mathrm{B}}-\mathrm{P}_{0}^{\mathrm{A}}$ is proportional to differentiation $\Theta^{\mathrm{AB}}$ for small differentiation, i.e., $\mathrm{P}_{0}^{\mathrm{B}}-\mathrm{P}_{0}^{\mathrm{A}} \sim \Theta^{\mathrm{AB}}$ for $\left|\Theta^{\mathrm{AB}}\right|<<1$, one can easily conclude from Eq. 8 and 10 that in first order by differentiation $\Theta^{\mathrm{AB}}$ :

$$
\begin{array}{ll}
\tau_{\mathrm{D}}^{\mathrm{B}}=\tau_{\mathrm{D}}^{\mathrm{A}}=\tau_{\mathrm{D}} ; & \tau_{\mathrm{S}}^{\mathrm{B}}=\tau_{\mathrm{s}}^{\mathrm{A}}=\tau_{\mathrm{s}} ; \\
\mathrm{C}_{\mathrm{D}}^{\mathrm{AB}}=\mathrm{C}_{\mathrm{D}} ; & \mathrm{C}_{\mathrm{S}}^{\mathrm{AB}}=\mathrm{C}_{\mathrm{S}}
\end{array}
$$

So we will use the same $\tau_{\mathrm{D}}$ and $\tau_{\mathrm{S}}$ for all derivatives of demand and supply curves for both products $\mathrm{A}$ and $\mathrm{B}$ in a vicinity of their market equilibrium. Eq. 13 means that demand and supply curves do not show any skew in the first order by small differentiation $\Theta^{\mathrm{AB}}$.

The equilibrium Eq. 10 can be rewritten as:

$$
\begin{aligned}
& \mathrm{Q}_{0}^{\mathrm{B}}=\mathrm{Q}_{0}^{\mathrm{A}}-\tau_{\mathrm{D}}\left(\mathrm{P}_{0}^{\mathrm{B}}-\mathrm{P}_{0}^{\mathrm{A}}-\mathrm{C}_{\mathrm{D}} \Theta^{\mathrm{AB}}\right)-\lambda \mathrm{C}_{\mathrm{D}} \Theta^{\mathrm{AB}} \\
& \mathrm{Q}_{0}^{\mathrm{B}}=\mathrm{Q}_{0}^{\mathrm{A}}+\tau_{\mathrm{S}}\left(\mathrm{P}_{0}^{\mathrm{B}}-\mathrm{P}_{0}^{\mathrm{A}}-\mathrm{C}_{\mathrm{S}} \Theta^{\mathrm{AB}}\right)
\end{aligned}
$$

Solved together, Eq. 14 provides linear approximation for equilibrium point $\left(\mathrm{P}_{0}^{\mathrm{B}}, \mathrm{Q}_{0}^{\mathrm{B}}\right)$ for product $\mathrm{B}$ expressed in terms of equilibrium point $\left(\mathrm{P}_{0}^{\mathrm{A}}, \mathrm{Q}_{0}^{\mathrm{A}}\right)$ for product $A$ and small differentiation $\Theta^{\mathrm{AB}}$ :

$$
\begin{aligned}
& \mathrm{P}_{0}^{\mathrm{B}}=\mathrm{P}_{0}^{\mathrm{A}}+\frac{\tau_{\mathrm{D}} \mathrm{C}_{\mathrm{D}}+\tau_{\mathrm{S}} \mathrm{C}_{\mathrm{S}}-\lambda \mathrm{C}_{\mathrm{D}}}{\tau_{\mathrm{D}}+\tau_{\mathrm{S}}} \Theta^{\mathrm{AB}} \\
& \mathrm{Q}_{0}^{\mathrm{B}}=\mathrm{Q}_{0}^{\mathrm{A}}+\tau_{\mathrm{S}} \frac{\tau_{\mathrm{D}}\left(\mathrm{C}_{\mathrm{D}}-\mathrm{C}_{\mathrm{S}}\right)-\lambda \mathrm{C}_{\mathrm{D}}}{\tau_{\mathrm{D}}+\tau_{\mathrm{S}}} \Theta^{\mathrm{AB}}
\end{aligned}
$$

As it is clear from Eq. 14 parameters $\tau_{D}$ and $\tau_{\mathrm{S}}$ are actually price derivatives of the demand and supply lines in equilibrium for products A and B. For this reason, one can express these parameters in terms of price elasticity of demand and supply in the equilibrium, i.e. Eq. 16:

$\tau_{\mathrm{D}}=\frac{\mathrm{Q}_{0}^{\mathrm{A}}}{\mathrm{P}_{0}^{\mathrm{A}}} \mathrm{E}_{\mathrm{D} 0}^{\mathrm{A}}=\frac{\mathrm{Q}_{0}^{\mathrm{B}}}{\mathrm{P}_{0}^{\mathrm{B}}} \mathrm{E}_{\mathrm{D} 0}^{\mathrm{B}} \quad$ and $\quad \tau_{\mathrm{s}}^{\mathrm{A}}=\frac{\mathrm{Q}_{0}^{\mathrm{A}}}{\mathrm{P}_{0}^{\mathrm{A}}} \mathrm{E}_{\mathrm{S} 0}^{\mathrm{A}}$

where, $\mathrm{E}_{\mathrm{D} 0}^{\mathrm{A}}$ and $\mathrm{E}_{\mathrm{D} 0}^{\mathrm{B}}$ are price elasticity of demand and $\mathrm{E}_{\mathrm{S} 0}^{\mathrm{A}}$ and $\mathrm{E}_{\mathrm{S} 0}^{\mathrm{B}}$ are price elasticity of supply for products $\mathrm{A}$ and $B$ in their equilibrium. Price elasticity of demand and price elasticity of supply are defined as follows Eq. 17:

$E_{D}=-\frac{P}{Q_{D}} \frac{d Q_{D}}{d P} \quad$ and $\quad E_{S}=\frac{P}{Q_{S}} \frac{d Q_{S}}{d P}$

Similarly, we define a differentiation elasticity of demand that is a percentage change of the demand sag (negative shift along quantity axis) over the percentage 
change of the horizontal (positive shift along the price axis) demand shift due to differentiation according to Eq. 6 and Eq. 18:

$$
\mathrm{E}_{\Theta}=\frac{\mathrm{P}}{\mathrm{Q}_{\mathrm{D}}} \frac{\Delta \mathrm{Q}_{\mathrm{D}}}{\Delta \mathrm{P}_{\mathrm{D}}}=\lambda \frac{\mathrm{P}}{\mathrm{Q}_{\mathrm{D}}}
$$

Or for equilibrium point $\left(\mathrm{P}_{0}^{\mathrm{A}}, \mathrm{Q}_{0}^{\mathrm{A}}\right)$ Eq. 19:

$$
\mathrm{E}_{\Theta}=\frac{\mathrm{P}_{0}^{\mathrm{A}}}{\mathrm{Q}_{0}^{\mathrm{A}}} \frac{\Delta \mathrm{Q}_{\mathrm{D}}^{\mathrm{AB}}}{\Delta \mathrm{P}_{\mathrm{D}}^{\mathrm{AB}}}=\lambda \frac{\mathrm{P}_{0}^{\mathrm{A}}}{\mathrm{Q}_{0}^{\mathrm{A}}}
$$

Differentiation elasticity of demand $E_{\Theta}$ is not defined on a single demand curve with varying price like price elasticity of demand $E_{D}$ or supply $E_{D}$. Price elasticity of demand $E_{D}$ or supply $E_{S}$ both describe a specific property of product quantities along a single demand or a single supply line with changes in price. In contrast, $\mathrm{E}_{\Theta}$ is defined on the demand curve shift and sag caused by differentiation and describes morphing properties of the demand curve caused by differentiation.

Note that though the demand lines for products $A$ and $\mathrm{B}$ have equal slopes at the appropriate market equilibrium points as well as the supply lines, in general $\mathrm{E}_{\mathrm{D} 0}^{\mathrm{A}} \neq \mathrm{E}_{\mathrm{D} 0}^{\mathrm{B}}$ and $\mathrm{E}_{\mathrm{S} 0}^{\mathrm{A}} \neq \mathrm{E}_{\mathrm{S} 0}^{\mathrm{B}}$ due to differences in equilibrium quantities and prices. Similarly, $\mathrm{E}_{\Theta 0}^{\mathrm{A}} \neq \mathrm{E}_{\Theta 0}^{\mathrm{B}}$.

The equilibrium price and quantity for product $B$ shown in Eq. 15 can be rewritten in terms of elasticity, $\mathrm{E}_{\mathrm{D} 0}^{\mathrm{A}}, \mathrm{E}_{\mathrm{S} 0}^{\mathrm{A}}$ and $\mathrm{E}_{\Theta 0}^{\mathrm{A}}$ according to Eq. 16 and 20:

$$
\begin{aligned}
& \mathrm{P}_{0}^{\mathrm{B}}=\mathrm{P}_{0}^{\mathrm{A}}+\frac{\mathrm{E}_{\mathrm{D} 0}^{\mathrm{A}} \mathrm{C}_{\mathrm{D}}+\mathrm{E}_{\mathrm{S} 0}^{\mathrm{A}} \mathrm{C}_{\mathrm{S}}-\mathrm{E}_{\Theta 0}^{\mathrm{A}} \mathrm{C}_{\mathrm{D}}}{\mathrm{E}_{\mathrm{D} 0}^{\mathrm{A}}+\mathrm{E}_{\mathrm{S} 0}^{\mathrm{A}}} \Theta^{\mathrm{AB}} \\
& \mathrm{Q}_{0}^{\mathrm{B}}=\mathrm{Q}_{0}^{\mathrm{A}}+\frac{\mathrm{Q}_{0}^{\mathrm{A}}}{\mathrm{P}_{0}^{\mathrm{A}}} \mathrm{E}_{\mathrm{S} 0}^{\mathrm{A}} \frac{\mathrm{E}_{\mathrm{D} 0}^{\mathrm{A}}\left(\mathrm{C}_{\mathrm{D}}-\mathrm{C}_{\mathrm{S}}\right)-\mathrm{E}_{\Theta 0}^{\mathrm{A}} \mathrm{C}_{\mathrm{D}}}{\mathrm{E}_{\mathrm{D} 0}^{\mathrm{A}}+\mathrm{E}_{\mathrm{S} 0}^{\mathrm{A}}} \Theta^{\mathrm{AB}}
\end{aligned}
$$

Market mix of products with small differentiation: A general approach: Consider a market that consists of a group $\mathfrak{R}$ of similar products, i.e., $\mathrm{N}$ different products with small differentiation between each other. Assume demand and supply for each product $\mathrm{n}(\mathrm{n}=1$, $\ldots, N$ ) is in equilibrium. Then according to Eq. 15 the equilibrium price $\mathrm{P}_{0}^{\mathrm{n}}$ and quantity $\mathrm{Q}_{0}^{\mathrm{n}}$ for each product $\mathrm{n}$ can be expressed in terms of equilibrium price $\mathrm{P}_{0}^{\mathrm{m}}$ and quantity $\mathrm{Q}_{0}^{\mathrm{m}}$ of another product $\mathrm{m}$ of group $\mathfrak{R}$ slightly modified with the appropriate differentiation $\Theta^{\mathrm{mn}}$. Product $\mathrm{m}$ is referred to as a reference product:

$$
\begin{aligned}
& \mathrm{P}_{0}^{\mathrm{n}}=\mathrm{P}_{0}^{\mathrm{m}}+\frac{\tau_{\mathrm{D}} \mathrm{C}_{\mathrm{D}}+\tau_{\mathrm{S}} \mathrm{C}_{\mathrm{S}}-\lambda \mathrm{C}_{\mathrm{D}}}{\tau_{\mathrm{D}}+\tau_{\mathrm{S}}} \Theta^{\mathrm{mn}} \\
& \mathrm{Q}_{0}^{\mathrm{n}}=\mathrm{Q}_{0}^{\mathrm{m}}+\tau_{\mathrm{S}} \frac{\tau_{\mathrm{D}}\left(\mathrm{C}_{\mathrm{D}}-\mathrm{C}_{\mathrm{S}}\right)-\lambda \mathrm{C}_{\mathrm{D}}}{\tau_{\mathrm{D}}+\tau_{\mathrm{S}}} \Theta^{\mathrm{mn}}
\end{aligned}
$$

where, $\tau_{\mathrm{D}}$ and $\tau_{\mathrm{S}}$ are the slopes of the demand and supply lines correspondently. As it was shown above (see Eq. 13), in the linear approximation by differentiation the appropriate slopes $\tau_{\mathrm{D}}$ and $\tau_{\mathrm{S}}$ are the same correspondently for all products of group $\Re$ Eq. 22 :

$$
\tau_{\mathrm{D}}^{\mathrm{n}}=\tau_{\mathrm{D}} \text { and } \tau_{\mathrm{S}}^{\mathrm{n}}=\tau_{\mathrm{S}} \text { for alln }=1, \ldots, \mathrm{N}
$$

As well as the price markup rates and the demand sag rate are uniform across all products in group $\mathfrak{K}$ as shown in Eq. 23:

$$
\begin{aligned}
& C_{D}^{m n}=C_{D} \\
& C_{S}^{m n}=C_{S} \\
& \lambda^{m n}=\lambda
\end{aligned}
$$

Note that each product in group $\mathfrak{R}$ is in its market equilibrium and the equilibrium price for each product is different from the equilibrium price for other products in the group due to product differentiations. Thus there is no single equilibrium price for the entire group $\mathfrak{R}$ because each product is sold at its own equilibrium price $\mathrm{P}_{0}^{\mathrm{n}}$, different from the equilibrium prices for other products in the group. On the other hand, the total equilibrium quantity $\mathrm{Q}_{0}$ for the entire group $\mathfrak{R}$ is the sum of equilibrium quantities of each product $\mathrm{Q}_{0}^{\mathrm{n}}$ of the group at its own equilibrium price $\mathrm{P}_{0}^{\mathrm{n}}$. The average equilibrium quantity in the group, $\overline{\mathrm{Q}_{0}}$, per each type of product in the group equals $\mathrm{Q}_{0} / \mathrm{N}$. Though a single equilibrium price within group $\mathfrak{R}$ does not exist, the average price for the group $\overline{\mathrm{P}_{0}}$ makes good sense. The total equilibrium quantity $\mathrm{Q}_{0}$ and average price $\overline{\mathrm{P}_{0}}$ for the entire group $\mathfrak{R}$ can be calculated as follows Eq. 24:

$$
\begin{aligned}
& \mathrm{Q}_{0}=\sum_{\mathrm{n}=1}^{\mathrm{N}} \mathrm{Q}_{0}^{\mathrm{n}} \\
& \overline{\mathrm{Q}_{0}}=\frac{\mathrm{Q}_{0}}{\mathrm{~N}}=\frac{1}{\mathrm{~N}} \sum_{\mathrm{n}=1}^{\mathrm{N}} \mathrm{Q}_{0}^{\mathrm{n}} \\
& \overline{\mathrm{P}_{0}}=\frac{1}{\mathrm{Q}_{0}} \sum_{\mathrm{n}=1}^{\mathrm{N}} \mathrm{P}_{0}^{\mathrm{n}} \mathrm{Q}_{0}^{\mathrm{n}}
\end{aligned}
$$

Taking $\mathrm{Q}_{0}^{\mathrm{n}}$ and $\mathrm{P}_{0}^{\mathrm{n}}$ from Eq. 21 and using them in Eq. 24 one obtains Eq. 25:

$$
\begin{aligned}
& \mathrm{Q}_{0}=\mathrm{NQ}_{0}^{\mathrm{m}}+\tau_{\mathrm{S}} \frac{\tau_{\mathrm{D}}\left(\mathrm{C}_{\mathrm{D}}-\mathrm{C}_{\mathrm{S}}\right)-\lambda \mathrm{C}_{\mathrm{D}}}{\tau_{\mathrm{D}}+\tau_{\mathrm{S}}} \sum_{\mathrm{n}=1}^{\mathrm{N}} \Theta^{\mathrm{mn}} \\
& \overline{\mathrm{P}_{0}}=\mathrm{P}_{0}^{\mathrm{m}}\left(1+\frac{\tau_{\mathrm{D}} \mathrm{C}_{\mathrm{D}}+\tau_{\mathrm{S}} \mathrm{C}_{\mathrm{S}}-\lambda \mathrm{C}_{\mathrm{D}}}{\tau_{\mathrm{D}}+\tau_{\mathrm{S}}} \sum_{\mathrm{n}=1}^{\mathrm{N}} \Theta^{\mathrm{mn}}\right)
\end{aligned}
$$


Symmetric approach and average products: As soon as a reference product $\mathrm{m}$ in the group can be selected arbitrarily, let's select product A as an average product of group $\mathfrak{R}$ to be a reference product within group $\Re$, such as:

$$
\sum_{\mathrm{n}=1}^{\mathrm{N}} \Theta^{\mathrm{An}}=0
$$

Product $A$ can be a real product in group $\Re$ if such a product exists or a virtual product used just as an average reference point. Then from Eq. 25 and 26 it follows that Eq. 27:

$$
\begin{aligned}
& \mathrm{Q}_{0}=\mathrm{NQ}_{0}^{\mathrm{A}} \\
& \overline{\mathrm{P}_{0}}=\mathrm{P}_{0}^{\mathrm{A}}
\end{aligned}
$$

Then $\mathrm{Q}_{0}^{\mathrm{n}}$ and $\mathrm{P}_{0}^{\mathrm{n}}$ for each individual product $\mathrm{n}$ from group $\Re$ can be calculated as of Eq. 26 with differentiation $\Theta^{\mathrm{An}}$ relative to the average product $A$.

It is important to clearly understand that there is a total equilibrium quantity $\mathrm{Q}_{0}$ for the products of group $\Re$ but the equilibrium prices for different products from the group are different, i.e., $\mathrm{P}_{0}^{\mathrm{n}} \neq \mathrm{P}_{0}^{\mathrm{j}}$ for any $\mathrm{n} \neq \mathrm{j}$ in group $\Re$ if $\Theta_{0}^{\mathrm{nj}} \neq 0$ due to differentiation. The average price $\overline{\mathrm{P}_{0}}$ is just an average equilibrium price for the group but may not be an equilibrium price for any actual product of group R. Each product in the group has its own equilibrium price and quantity as it is clearly seen from Fig. 2. Product $m$ in Fig. 2 may be a virtual product that meets the conditions of Eq. 26. Due to the differentiation between products of group $\Re$ and the absence of a single equilibrium point, one cannot apply the concept of demand and supply equilibrium to the entire group $\Re$ as a whole because the products are slightly different and hence their equilibrium prices are different too. This kind of situation is quite common because there are no absolutely similar products in real world markets.

A legitimate question arises, how applicable is the demand-supply theory to any market, particularly to a near-perfectly competitive market, if there is no single equilibrium price for any group of products even with the slightest differentiation. Is economic theory just an abstract exercise or can it be practically applied to solve real world problems? In the next part of this article, we will try to provide an answer to the question posed above by introducing the concept of price-value potential.

\section{Price-value potential:}

Definition of price-value potential: Let's introduce price-value potential, $\phi$, that will be used in place of price in market analysis and modeling Eq. 28:

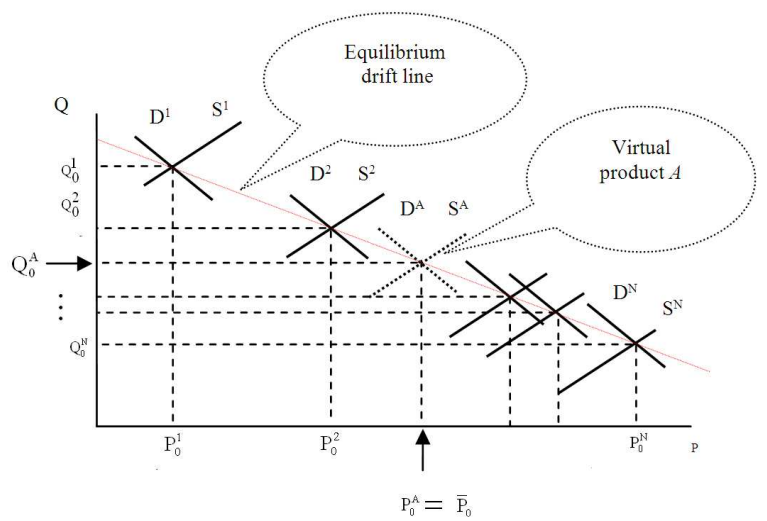

Fig. 2: Local equilibriums for slightly different products in a near-perfectly competitive market

$\varphi=\mathrm{P}-\mathrm{V}$

where, $\mathrm{P}$ stands for price and $\mathrm{V}$ for value. Value depends on the product feature set, on consumer perception and willingness to buy and on the market in general. Value can be expressed as Eq. 29:

$\mathrm{V}=\mathrm{V}_{\mathrm{F}}+\mathrm{V}_{0}$

where, $V_{F}$ is the market value of the product feature set $\mathrm{F}$ and $\mathrm{V}_{0}$ is a constant value independent of product features but related to the market in general. Value is a complex concept that cannot be understood simplistically; it is a perceptional entity that is not based on cost or savings only.

By analogy, the concept of price-value potential is similar to the concept of free energy or thermodynamic potential in physics (Landau and Lifshitz, 1980; Reiss, 1996), where money can be understood as virtual energy in economics (Landau and Lifshitz, 1980). Like in any potential field, an absolute value of the pricevalue potential is not important while a difference of potentials and their gradients produces work and is significant for dynamics and equilibrium analyses. For this reason an accurate definition of value in Eq. 28 and 29 is not as important as an accurate definition of differences of value.

Any small differentiation of the product feature set $F$ results in small changes of value $\mathrm{V}$ as Eq. 30:

$\Delta \mathrm{V}=\Delta \mathrm{V}_{\mathrm{F}}=\mathrm{G} \Theta=\sum_{\mathrm{k}=1}^{\mathrm{K}} \mathrm{g}_{\mathrm{k}} \theta_{\mathrm{k}}$

where, $\Delta \mathrm{V}$ is value differentiation, i.e., the difference of product equilibrium values due to differentiation, $\mathrm{G}$ is a vector of value change rates that shows a change rate of the product value vector per one percent of differentiation, $\mathrm{G}=\left(\mathrm{g}_{1}, \mathrm{~g}_{2}, \ldots . \mathrm{g}_{\mathrm{k}}\right)$ and $\Theta$ is the 
differentiation vector, $\Theta=\left(\theta_{1}, \theta_{2}, \ldots \theta_{\mathrm{k}}\right)$, against the reference feature set. The difference between vector $G$ in Eq. 30 and vectors $C_{D}$ and $C_{S}$ in Eq. 3 is that vector $\mathrm{G}$ identifies a shift of the market equilibrium points while vectors $C_{D}$ and $C_{S}$ determine shifts of the demand and supply curves correspondingly due to differentiation $\Theta$. With small differentiation, the total value differentiation $\Delta \mathrm{V}$ can be represented as a linear expansion of the value differentiations. According to Eq. 15 the value differentiation of Eq. 30 can be written as Eq. 31:

$$
\Delta \mathrm{V}=\frac{\tau_{\mathrm{D}} \mathrm{C}_{\mathrm{D}}+\tau_{\mathrm{S}} \mathrm{C}_{\mathrm{S}}-\lambda \mathrm{C}_{\mathrm{D}}}{\tau_{\mathrm{D}}+\tau_{\mathrm{S}}} \Theta
$$

and the total difference of the price-value potential as:

$$
\Delta \varphi=\Delta \mathrm{P}-\frac{\tau_{\mathrm{D}} \mathrm{C}_{\mathrm{D}}+\tau_{\mathrm{S}} \mathrm{C}_{\mathrm{S}}-\lambda \mathrm{C}_{\mathrm{D}}}{\tau_{\mathrm{D}}+\tau_{\mathrm{S}}} \Theta
$$

where, $\tau_{\mathrm{D}}$ and $\tau_{\mathrm{S}}$ are the appropriate slopes of the demand and supply curves, $C_{D}$ and $C_{S}$ are the appropriate shift rates for the demand and supply lines, $\lambda C_{D}$ is the demand sag and $\Theta$ is a differentiation of feature set $F$ of the product as defined earlier in the study.

Price-value potential conservation principle: Let's introduce a cross-product price-value conservation principle that defines the cross-product market equilibrium condition. The conservation principle states that the equilibrium price-value potential is constant for all products in a balanced economy where all markets are in equilibrium, i.e., the differentiation gradient of price-value potential is zero in equilibrium Eq. 33:

$$
\nabla_{\Theta} \varphi_{0}=0
$$

where, $\Delta \Theta \phi_{0}$ is the gradient of the equilibrium pricevalue potential over all products in equilibrium markets. The meaning of the conservation law is that crossproduct equilibrium on the market is dynamically flowing from the higher price-value potentials towards lower ones until all price-value potentials in crossproduct equilibrium reach the same level. Similarly to free energy or thermodynamic potential in statistical physics (Landau and Lifshitz, 1980; Reiss, 1996), the minimum of price-value potential can be used in market analysis as a condition for a steady state or equilibrium.

Assuming that all products in group $\mathfrak{R}$ are in crossproduct market equilibrium, then, according to the conservation principle the equilibrium price-value potential for all products in group $\Re$ has to be the same for all differentiations, i.e.:

$$
\frac{\Delta \varphi_{0}^{\mathrm{AB}}}{\Delta \Theta^{\mathrm{AB}}}=0 \quad \text { or } \quad \Delta \varphi_{0}^{\mathrm{AB}}=0
$$

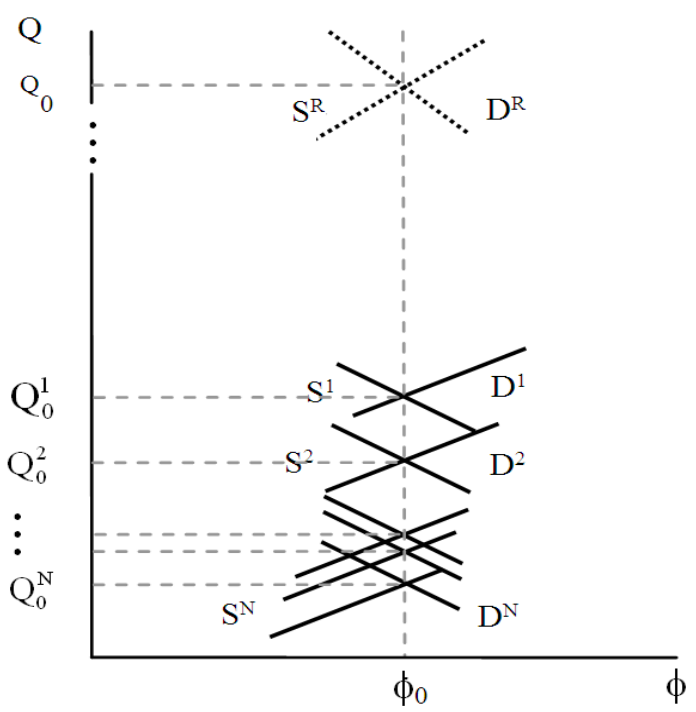

Fig. 3: Market equilibriums for different products with small differentiation in terms of pricevalue potential

For any two products $\mathrm{A}$ and $\mathrm{B}$ in group $\mathfrak{R}$. The condition in Eq. 34 completely concurs with Eq. 32.

Market equilibrium for products with small differentiation: Applying the conservation principle $\Delta \varphi_{0}^{\mathrm{n}}=\Delta \varphi_{0}^{\mathrm{m}}$ stated in Eq. 34 to a group of products $\Re$ one can easily find that the equilibrium potentials for each product $\mathrm{n}$ in the group is:

$\Delta \mathrm{P}_{0}^{\mathrm{mn}}-\frac{\tau_{\mathrm{D}} \mathrm{C}_{\mathrm{D}}+\tau_{\mathrm{S}} \mathrm{C}_{\mathrm{S}}-\lambda \mathrm{C}_{\mathrm{D}}}{\tau_{\mathrm{D}}+\tau_{\mathrm{S}}} \Theta^{\mathrm{mn}}$

where, $\Delta \mathrm{P}_{0}^{\mathrm{mn}}$ is the difference between equilibrium prices for products $\mathrm{n}$ and $\mathrm{m}$ correspondingly. This result completely corresponds with the results of the traditional price-quantity approach shown in Eq. 35.

According to Eq. 28, 29 and 32 the demand and supply curves for each product $n$ in group $\mathfrak{R}$ can be rewritten in terms of price-value potential as:

$$
\begin{aligned}
& Q_{D}^{\mathrm{n}}(\varphi)=Q_{D}\left(P-P_{0}^{\mathrm{n}}\right) \\
& \mathrm{Q}_{S}^{\mathrm{n}}(\varphi)=Q_{D}\left(P-P_{0}^{\mathrm{n}}\right)
\end{aligned}
$$

where, $\mathrm{P}_{0}^{\mathrm{n}}$ is the equilibrium price for product $\mathrm{n}$ from group $\mathfrak{R}$. Demand and supply curves are presented in Eq. 36 as functions of price-value potential, $Q(\phi)$, rather than a function of just price, $\mathrm{Q}(\mathrm{P})$, as in classic economic theory. Then the condition for market equilibrium for product $\mathrm{n}$ is: 
$\mathrm{Q}_{\mathrm{D}}^{\mathrm{n}}\left(\varphi_{0}^{\mathrm{n}}\right)=\mathrm{Q}_{\mathrm{S}}^{\mathrm{n}}\left(\varphi_{0}^{\mathrm{n}}\right)$

It is quite clear from Eq. 36 that price-value potential in market equilibrium is equal for all products of group $\mathfrak{R}$ as shown in Eq. 38 and in Fig. 3:

$\varphi_{0}^{1}=\cdots=\varphi_{0}^{\mathrm{n}}=\cdots=\varphi_{0}^{\mathrm{N}}=\varphi_{0}$

As it is clearly seen from Eq. 37 and Fig. 3, the equilibrium price-value potentials for all products of group $\Re$ are all equal, thus meeting the conservation principle of Eq. 34. Each product from group $\mathfrak{R}$ has the same equilibrium potential $\phi_{0}$ and its own equilibrium quantity $\mathrm{Q}_{0}^{\mathrm{n}}$. Thus the cross-product market equilibrium for group $\mathfrak{R}$ is represented by the equilibrium point of price-value potential and quantities $\left(\phi_{0}, \mathrm{Q}_{0}\right)$ where Eq. 39:

$\mathrm{Q}_{0}\left(\varphi_{0}\right)=\sum_{\mathrm{n}=1}^{\mathrm{N}} \mathrm{Q}_{0}^{\mathrm{n}}\left(\varphi_{0}\right)$

Product pricing, average price and total quantity for a group of products with small differentiation: Products of group $\Re$ are in market equilibrium with the same price-value potential $\phi_{0}$ and total quantity $\mathrm{Q}_{0}$ for the entire group $\mathfrak{R}$. However, each product $\mathrm{n}(\mathrm{n}=1$, $2, \ldots, N$ ) in the group shows a small differentiation from other products in the group. Differentiation can be measured relative to any product $m$ in group $\mathfrak{R}$. For all products of group $\Re$ the equilibrium price-value potential is the same, i.e., $\Delta \varphi_{0}^{\mathrm{mn}}=0$, but the differentiation value is different according to Eq. 38 . Then the equilibrium price and quantity for product $\mathrm{n}$ relative to reference product $m$ in group $\Re$ are Eq. 40:

$$
\begin{aligned}
& \mathrm{P}_{0}^{\mathrm{n}}=\mathrm{P}_{0}^{\mathrm{m}}+\frac{\tau_{\mathrm{D}} \mathrm{C}_{\mathrm{D}}+\tau_{\mathrm{S}} \mathrm{C}_{\mathrm{S}}-\lambda \mathrm{C}_{\mathrm{D}}}{\tau_{\mathrm{D}}+\tau_{\mathrm{S}}} \Theta^{\mathrm{mn}} \\
& \mathrm{Q}_{0}^{\mathrm{n}}=\mathrm{Q}_{0}^{\mathrm{m}}+\tau_{\mathrm{s}} \frac{\tau_{\mathrm{D}}\left(\mathrm{C}_{\mathrm{D}}-\mathrm{C}_{\mathrm{S}}\right)-\lambda \mathrm{C}_{\mathrm{D}}}{\tau_{\mathrm{D}}+\tau_{\mathrm{S}}} \Theta^{\mathrm{mn}}
\end{aligned}
$$

The difference of the equilibrium prices and quantities between products $n$ and $m$ in group $\Re$ are:

$$
\begin{aligned}
& \Delta \mathrm{P}_{0}^{\mathrm{nm}}=\mathrm{P}_{0}^{\mathrm{n}}-\mathrm{P}_{0}^{\mathrm{m}}=\frac{\tau_{\mathrm{D}} \mathrm{C}_{\mathrm{D}}+\tau_{\mathrm{S}} \mathrm{C}_{\mathrm{S}}-\lambda \mathrm{C}_{\mathrm{D}}}{\tau_{\mathrm{D}}+\tau_{\mathrm{S}}} \Theta^{\mathrm{mn}} \\
& \Delta \mathrm{Q}_{0}^{\mathrm{nm}}=\mathrm{Q}_{0}^{\mathrm{n}}-\mathrm{Q}_{0}^{\mathrm{m}}=\tau_{\mathrm{s}} \frac{\tau_{\mathrm{D}}\left(\mathrm{C}_{\mathrm{D}}-\mathrm{C}_{\mathrm{S}}\right)-\lambda \mathrm{C}_{\mathrm{D}}}{\tau_{\mathrm{D}}+\tau_{\mathrm{S}}} \Theta^{\mathrm{mn}}
\end{aligned}
$$

The average equilibrium price and the total equilibrium quantity of all products in group $\Re$ can be calculated according to the definitions of these parameters given in Eq. 24 and equilibrium prices and quantities for each product shown in Eq. 41 and calculated from the price-value potential conservation principle of Eq. 34:

$$
\begin{aligned}
& \overline{P_{0}}=P_{0}^{m}+\frac{\tau_{D} C_{D}+\tau_{S} C_{S}-\lambda C_{D}}{\tau_{D}+\tau_{S}} \sum_{n=1}^{N} \Theta^{m n} \\
& Q_{0}=N Q_{0}^{m}+\tau_{S} \frac{\tau_{D}\left(C_{D}-C_{S}\right)-\lambda C_{D}}{\tau_{D}+\tau_{S}} \sum_{n=1}^{N} \Theta^{m n} \\
& \overline{Q_{0}}=\frac{Q_{0}}{N}=Q_{0}^{m}+\frac{1}{N} \tau_{s} \frac{\tau_{D}\left(C_{D}-C_{S}\right)-\lambda C_{D}}{\tau_{D}+\tau_{S}} \sum_{n=1}^{N} \Theta^{m n}
\end{aligned}
$$

where, $\mathrm{m}$ is any product in group $\mathfrak{R}$ taken as a point of reference for differentiation.

Product pricing relative to average price: Differentiation $\Theta^{\mathrm{mn}}$ can be measured relative to any product in group $\mathfrak{R}$. However, it is convenient to measure the differentiation relative to the average product in the group. Average product A is defined as one which has a differentiation that is equal to the average of all differentiations within the group, such as:

$\sum_{n=1}^{N} \Theta^{A n}=0$

If a real average product does not exist in the group, the average product A can be defined as a virtual one. The average product can be found or virtually defined as Eq. 44:

$$
\Theta^{\mathrm{mA}}=\sum_{\mathrm{n}=1}^{\mathrm{N}} \Theta^{\mathrm{mn}}
$$

That leads to condition in Eq. 43 to become Eq. 45:

$$
\sum_{n=1}^{N} \Theta^{A n}=\sum_{n=1}^{N}\left(\Theta^{A m}+\sum_{n=1}^{N} \Theta^{m n}\right)=\sum_{n=1}^{N}\left(\Theta^{A m}+\Theta^{m A}\right)=0
$$

Then according to Eq. 42 and 43 and taking into account that $\Theta^{\mathrm{AA}}=0$, the average equilibrium price $\overline{\mathrm{P}_{0}}$ and total quantity $\mathrm{Q}_{0}$ are related to the equilibrium price and quantity for the average product $\mathrm{A}$ of group $\mathfrak{R}$ as:

$$
\begin{aligned}
& \mathrm{Q}_{0}^{\mathrm{A}}=\frac{\mathrm{Q}_{0}}{\mathrm{~N}} \\
& \mathrm{P}_{0}^{\mathrm{A}}=\overline{\mathrm{P}_{0}}
\end{aligned}
$$


where, $\mathrm{Q}_{0}$ and $\overline{\mathrm{P}_{0}}$ are the total equilibrium quantity and average price of the products in group $\mathfrak{R}$. According to Eq. 40 and 46 the differentiation adjusted price for each product $\mathrm{n}$ from group $\mathfrak{R}$ is Eq. 47 :

$$
\begin{aligned}
& \mathrm{P}_{0}^{\mathrm{n}}=\overline{\mathrm{P}_{0}}+\Delta \mathrm{P}_{0}^{\mathrm{n}} \\
& \mathrm{Q}_{0}^{\mathrm{n}}=\frac{\mathrm{Q}_{0}}{\mathrm{~N}}+\Delta \mathrm{Q}_{0}^{\mathrm{n}}
\end{aligned}
$$

where:

$$
\begin{aligned}
\Delta P_{0}^{n} & =\frac{\tau_{D} C_{D}+\tau_{S} C_{S}-\lambda C_{D}}{\tau_{D}+\tau_{S}} \Theta^{A n} \\
\Delta Q_{0}^{n} & =\tau_{S} \frac{\tau_{D}\left(C_{D}-C_{S}\right)-\lambda C_{D}}{\tau_{D}+\tau_{S}} \Theta^{A n}
\end{aligned}
$$

Replacing the demand and supply line slopes $\tau_{\mathrm{D}}$ and $\tau_{\mathrm{S}}$ in Eq. 48 with the appropriate elasticity as in Eq. 20 one can easily rewrite Eq. 46 in terms of elasticity:

$$
\begin{aligned}
& \Delta \mathrm{P}_{0}^{\mathrm{n}}=\frac{\mathrm{E}_{\mathrm{D} 0}^{\mathrm{A}} \mathrm{C}_{\mathrm{D}}+\mathrm{E}_{\mathrm{S} 0}^{\mathrm{A}} \mathrm{C}_{\mathrm{S}}-\mathrm{E}_{\Theta 0}^{\mathrm{A}} \mathrm{C}_{\mathrm{D}}}{\mathrm{E}_{\mathrm{D} 0}^{\mathrm{A}}+\mathrm{E}_{\mathrm{S} 0}^{\mathrm{A}}} \Theta^{\mathrm{An}} \\
& \Delta \mathrm{Q}_{0}^{\mathrm{n}}=\frac{\mathrm{Q}_{0}}{\mathrm{~N}_{0}} \mathrm{E}_{\mathrm{S} 0}^{\mathrm{A}} \frac{\mathrm{E}_{\mathrm{D} 0}^{\mathrm{A}}\left(\mathrm{C}_{\mathrm{D}}-\mathrm{C}_{\mathrm{S}}\right)-\mathrm{E}_{\Theta 0}^{\mathrm{A}} \mathrm{C}_{\mathrm{D}}}{\mathrm{E}_{\mathrm{D} 0}^{\mathrm{A}}+\mathrm{E}_{\mathrm{S} 0}^{\mathrm{A}}} \Theta^{\mathrm{An}}
\end{aligned}
$$

where, $\mathrm{E}_{\mathrm{D} 0}^{\mathrm{A}}$ and $\mathrm{E}_{\mathrm{S} 0}^{\mathrm{A}}$ are price elasticity of demand and supply and $\mathrm{E}_{\Theta 0}^{\mathrm{A}}$ is the differentiation elasticity of demand for the average product in group $\mathfrak{R}$ as defined in Eq. 17 and 18.

Price-value potential for a near-perfectly competitive market: Firms in a perfectly competitive market are price takers in classical economic theory. However, classical theory fails to suggest price variation in the case of small product differentiations on near-perfectly competitive markets. The pricevalue potential used instead of price for market equilibrium solves this problem.

Market equilibrium in terms of price-value potential for products with small differentiations in a near-perfectly competitive market is presented in Fig. 4 in accordance with the definition of price-value potential in Eq. 28 the market equilibrium price-value potential conservation condition in Eq. 38 and market equilibrium shown in Fig. 3.

Consider a near-perfectly competitive market which consists of a group $\mathfrak{R}$ of products with small differentiations. All products in the group have the same price-value potential $\phi_{0}$ in market equilibrium but their differentiations result in differences in values according to Eq. 29 and 31. Differences in product values result in differences in product pricing according to Eq. 32 and 49 and the price-value potential conservation condition of Eq. 38 .

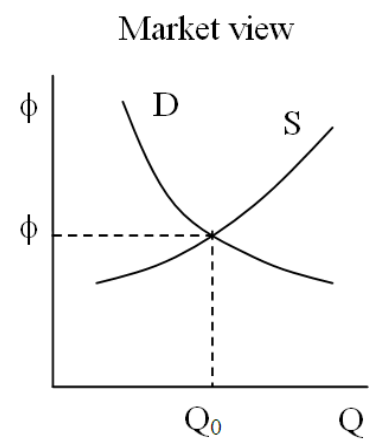

(a)

$$
\text { Firm's view }
$$

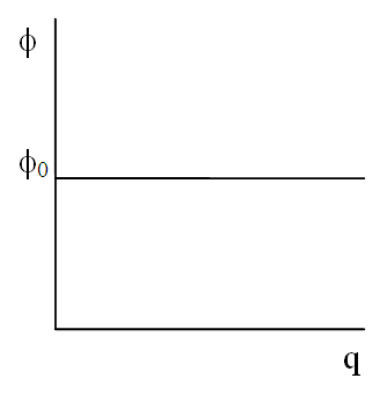

(b)

Fig. 4: Market equilibrium in terms of price-value potential (a) market view versus (b) a firm's view in the model of perfect competition

Demand and supply curves in Fig. 4 relate to all products in the market. In the market view price elasticity of demand and price elasticity of supply are $\mathrm{E}_{\mathrm{D} 0}^{\mathrm{A}}$ and $\mathrm{E}_{\mathrm{S} 0}^{\mathrm{A}}$. Price-value elasticity of demand $\phi_{\mathrm{D}}$ and price-value elasticity of supply $\phi_{\mathrm{S}}$ on this market can be defined as Eq. 50 and 51:

$$
\begin{aligned}
& \Phi_{\mathrm{D}}=-\frac{\varphi}{\mathrm{Q}_{\mathrm{D}}} \frac{\mathrm{dQ}}{\mathrm{d} \varphi} \text { and } \Phi_{\mathrm{S}}=\frac{\varphi}{\mathrm{Q}_{\mathrm{S}}} \frac{\mathrm{dQ}_{\mathrm{S}}}{\mathrm{d} \varphi} \\
& \Phi_{\mathrm{D}}=-\frac{\mathrm{P}-\mathrm{P}_{0}-\mathrm{V}_{0}}{\mathrm{Q}_{\mathrm{D}}} \frac{\mathrm{dQ}_{\mathrm{D}}}{\mathrm{d}\left(\mathrm{P}-\mathrm{P}_{0}-\mathrm{V}_{0}\right)}=-\frac{\mathrm{P}-\mathrm{P}_{0}-\mathrm{V}_{0}}{\mathrm{Q}_{\mathrm{D}}} \frac{\mathrm{dQ}_{\mathrm{D}}}{\mathrm{dP}} \\
& \Phi_{\mathrm{S}}=\frac{\mathrm{P}-\mathrm{P}_{0}-\mathrm{V}_{0}}{\mathrm{Q}_{\mathrm{S}}} \frac{\mathrm{dQ_{S }}}{\mathrm{d}\left(\mathrm{P}-\mathrm{P}_{0}-\mathrm{V}_{0}\right)}=-\frac{\mathrm{P}-\mathrm{P}_{0}-\mathrm{V}_{0}}{\mathrm{Q}_{\mathrm{S}}} \frac{\mathrm{dQ}}{\mathrm{dP}}
\end{aligned}
$$

Taking into account the definition of price-value potential in Eq. 28 and 29 one can derive that Eq. 52:

$\Phi_{\mathrm{D} 0}=-\frac{\mathrm{V}_{0}}{\mathrm{P}_{0}} \mathrm{E}_{\mathrm{D} 0} \quad$ and $\quad \Phi_{\mathrm{S} 0}=-\frac{\mathrm{V}_{0}}{\mathrm{P}_{0}} \mathrm{E}_{\mathrm{S} 0}$

Pricing on a strawberry market: Let's, as an example, analyze a strawberry market that is almost perfectly competitive. Suppose an average equilibrium 
price (per pound) and total equilibrium demands (in pounds) are Eq. 53:

$\overline{\mathrm{P}_{0}}=\$ 2.50 / \mathrm{lb} \quad$ and $\quad \mathrm{Q}_{0}=30,000 \mathrm{lb}$

However, strawberries sold on the market may show some differentiation. Suppose there are three kinds of strawberries on the market, $\alpha, \beta$ and $\gamma$. The average equilibrium demand per product is $\mathrm{Q}_{0}^{\mathrm{A}}=\mathrm{Q}_{0} / 3=10,000 \mathrm{lb}$. Strawberries of kind $\alpha$ are taken as the reference strawberries, i.e., all comparisons are made relative to strawberries $\alpha$. Please note that the reference product is not yet the average product. Strawberries of kind $\beta$ are $10 \%$ smaller in size, $20 \%$ sweeter and $10 \%$ more fragrant than strawberries of kind $\alpha$. Strawberries of kind $\gamma$ are $16 \%$ larger in size, $4 \%$ sweeter and 5\% more fragrant than strawberries of kind $\alpha$. We can say that strawberries show three types of differentiations, $\theta_{1}$ for size, $\theta_{2}$ for taste and $\theta_{3}$ for smell. Note that some features can be objectively measured (like size) while some other qualities are partially or completely subjective (like smell). Then the differentiations can be written as Eq. 54:

$$
\begin{array}{lll}
\theta_{1}^{\alpha \beta}=-10 \% ; & \theta_{2}^{\alpha \beta}=20 \% ; & \theta_{3}^{\alpha \beta}=10 \% ; \\
\theta_{1}^{\alpha \gamma}=16 \% ; & \theta_{2}^{\alpha \gamma}=4 \% ; & \theta_{3}^{\alpha \gamma}=5 \%
\end{array}
$$

Suppose the price markup rates for those differentiations are Eq. 55:

$$
\begin{array}{lll}
c_{D}^{1}=\$ 0.08 ; & c_{D}^{2}=\$ 0.11 ; & c_{D}^{3}=0.08 ; \\
c_{S}^{1}=\$ 0.08 ; & c_{S}^{2}=\$ 0.07 ; & c_{S}^{3}=0.09
\end{array}
$$

Per pound for each $1 \%$ of differentiation of the appropriate feature. Also suppose, just for example, that demand is slightly elastic, supply is slightly inelastic and differentiation elasticity of demand is slightly elastic, i.e., price elasticity of demand, $\mathrm{E}_{\mathrm{D} 0}$ and price elasticity of supply, $\mathrm{E}_{\mathrm{S} 0}$, as well as differentiation elasticity of demand, $\mathrm{E}_{\Theta 0}$, for the entire strawberry market are Eq. 56:

$$
\mathrm{E}_{\mathrm{D} 0}^{\alpha}=1.1 ; \quad \mathrm{E}_{\mathrm{S} 0}^{\alpha}=0.9 ; \quad \mathrm{E}_{\Theta 0}^{\alpha}=1.2
$$

The average product on this market does not exist in reality, so we introduce virtual strawberries of kind A with the average differentiation of all strawberries according to Eq. 44 and 57-58:

$$
\theta_{\mathrm{k}}^{\alpha \mathrm{A}}=\frac{1}{3} \sum_{\mathrm{x}=\alpha, \beta, \gamma} \theta_{\mathrm{k}}^{\alpha \mathrm{x}}
$$

Hence:

$$
\theta_{1}^{\alpha \mathrm{A}}=2 \% ; \quad \theta_{2}^{\alpha \mathrm{A}}=8 \% ; \quad \theta_{3}^{\alpha \mathrm{A}}=5 \% ;
$$

And the differentiations of all three products of the group relative to the average product A are Eq. 59:

$$
\begin{array}{lll}
\theta_{1}^{\mathrm{A} \alpha}=-2 \% ; & \theta_{2}^{\mathrm{A} \alpha}=-8 \% ; & \theta_{3}^{\mathrm{A} \alpha}=-5 \% ; \\
\theta_{1}^{\mathrm{A} \beta}=-12 \% ; & \theta_{2}^{\mathrm{A} \beta}=12 \% ; & \theta_{3}^{\mathrm{A} \beta}=5 \% ; \\
\theta_{1}^{\mathrm{A} \gamma}=14 \% ; & \theta_{2}^{\mathrm{A} \gamma}=-4 \% ; & \theta_{3}^{\mathrm{A} \gamma}=0 \%
\end{array}
$$

This means that according to Eq. 3 strawberries $\alpha$, $\beta$ and $\gamma$ have total demand and supply differentiation markups of Eq. 60:

$$
\begin{aligned}
& \mathrm{C}_{\mathrm{D}} \Theta^{A \alpha}=\sum_{\mathrm{k}=1}^{3} \mathrm{c}_{\mathrm{D}}^{\mathrm{k}} \mathrm{D}_{\mathrm{k}}^{\theta_{\mathrm{k}}}=-\$ 1.44 ; ; \quad \mathrm{C}_{\mathrm{S}} \Theta^{A \alpha}=\sum_{\mathrm{k}=1}^{3} \mathrm{c}_{\mathrm{S}}^{\mathrm{k}} \theta_{\mathrm{k}}^{A \alpha}=-\$ 1.17 ; \\
& C_{D} \Theta^{A \beta}=\sum_{k=1}^{3} c_{D}^{k} \theta_{k}^{A \beta}=\$ 0.76 ; ; \quad C_{S} \Theta^{A \beta}=\sum_{k=1}^{3} c_{S}^{k} \theta_{k}^{A \beta}=\$ 0.33 ; \\
& \mathrm{C}_{\mathrm{D}} \Theta^{A \gamma}=\sum_{\mathrm{k}=1}^{3} \mathrm{c}_{\mathrm{D}}^{\mathrm{k}} \mathrm{\theta}_{\mathrm{k}}^{A \gamma}=\$ 0.68 ; \quad \mathrm{C}_{\mathrm{s}} \Theta^{A \gamma}=\sum_{\mathrm{k}=1}^{3} \mathrm{c}_{\mathrm{s}}^{\mathrm{k}} \mathrm{\theta}_{\mathrm{k}}^{A \gamma}=\$ 0.84
\end{aligned}
$$

per pound relative to the average strawberries A. Do not forget that the average strawberries are virtual and were introduced only for the sake of a convenient point of reference. Then according to Eq. 49 one can find the difference of the equilibrium prices of strawberries $\alpha, \beta$ and $\gamma$ versus the average market price Eq. 61:

$$
\begin{aligned}
\Delta \mathrm{P}_{0}^{\alpha}= & \frac{\mathrm{E}_{\mathrm{D} 0} \mathrm{C}_{\mathrm{D}}+\mathrm{E}_{\mathrm{S} 0} \mathrm{C}_{\mathrm{S}}-\mathrm{E}_{\Theta 0} \mathrm{C}_{\mathrm{D}}}{\mathrm{E}_{\mathrm{D} 0}^{\mathrm{A}}+\mathrm{E}_{\mathrm{S} 0}^{\mathrm{A}}} \Theta^{\mathrm{A \alpha}} \\
& =\frac{-0.40-0.30-0.43}{1.1+0.9}=-\$ 0.13 \\
\Delta \mathrm{P}_{0}^{\beta} & =\frac{\mathrm{E}_{\mathrm{D} 0} \mathrm{C}_{\mathrm{D}}+\mathrm{E}_{\mathrm{S} 0} \mathrm{C}_{\mathrm{S}}-\mathrm{E}_{\Theta 0} \mathrm{C}_{\mathrm{D}}}{\mathrm{E}_{\mathrm{D} 0}^{\mathrm{A}}+\mathrm{E}_{\mathrm{S} 0}^{\mathrm{A}}} \Theta^{\mathrm{A} \beta} \\
& =\frac{0.37+0.24+0.41}{1.1+0.9}=\$ 0.10 \\
\Delta \mathrm{P}_{0}^{\gamma}= & \frac{\mathrm{E}_{\mathrm{D} 0} \mathrm{C}_{\mathrm{D}}+\mathrm{E}_{\mathrm{S} 0} \mathrm{C}_{\mathrm{S}}-\mathrm{E}_{\Theta 0} \mathrm{C}_{\mathrm{D}}}{\mathrm{E}_{\mathrm{D} 0}^{\mathrm{A}}+\mathrm{E}_{\mathrm{S} 0}^{\mathrm{A}}} \Theta^{\mathrm{A} \gamma} \\
& =\frac{0.02+0.05-0.02}{1.1+0.9}=\$ 0.03
\end{aligned}
$$

and the difference of the appropriate equilibrium quantities versus the average equilibrium quantity $\mathrm{Q}_{0}^{\mathrm{n}}$ per group Eq. 62:

$$
\begin{aligned}
\Delta \mathrm{Q}_{0}^{\alpha} & =\frac{\mathrm{Q}_{0} \mathrm{E}_{\mathrm{S} 0}}{\mathrm{P}_{0}} * \frac{\mathrm{E}_{\mathrm{D} 0}\left(\mathrm{C}_{\mathrm{D}}-\mathrm{C}_{\mathrm{S}}\right)-\mathrm{E}_{\Theta 0} \mathrm{C}_{\mathrm{D}}}{\mathrm{E}_{\mathrm{D} 0}+\mathrm{E}_{\mathrm{S} 0}} \Theta^{\mathrm{A} \alpha} \\
& =3600 \frac{-0.03+0.43}{0.9+1.1}=718 \mathrm{lb} \\
\Delta \mathrm{Q}_{0}^{\beta} & =\frac{\mathrm{Q}_{0} \mathrm{E}_{\mathrm{S} 0}}{\mathrm{~N} \overline{\mathrm{P}}_{0}} * \frac{\mathrm{E}_{\mathrm{D} 0}\left(\mathrm{C}_{\mathrm{D}}-\mathrm{C}_{\mathrm{S}}\right)-\mathrm{E}_{\Theta 0} \mathrm{C}_{\mathrm{D}}}{\mathrm{E}_{\mathrm{D} 0}+\mathrm{E}_{\mathrm{S} 0}} \Theta^{\mathrm{A} \alpha} \\
& =3600 \frac{0.08-0.41}{0.9+1.1}=-596 \mathrm{lb} \\
\Delta \mathrm{Q}_{0}^{\gamma} & =\frac{\mathrm{Q}_{0} \mathrm{E}_{\mathrm{S} 0}}{\mathrm{~N}_{0}} * \frac{\mathrm{E}_{\mathrm{D} 0}\left(\mathrm{C}_{\mathrm{D}}-\mathrm{C}_{\mathrm{S}}\right)-\mathrm{E}_{\Theta 0} \mathrm{C}_{\mathrm{D}}}{\mathrm{E}_{\mathrm{D} 0}+\mathrm{E}_{\mathrm{S} 0}} \Theta^{\mathrm{A} \alpha} \\
& =3600 \frac{-0.04-0.02}{0.9+1.1}=-122 \mathrm{lb}
\end{aligned}
$$


Am. J. of Economics and Business Administration 3 (4): 623-635, 2011

Table1: Equilibrium prices and quantities for strawberries $\alpha, \beta$ and $\gamma$

\begin{tabular}{|c|c|c|c|c|c|c|c|c|c|}
\hline \multirow[b]{3}{*}{ Product } & \multicolumn{3}{|c|}{$\begin{array}{l}\text { Differentiation vs } \\
\text { average product }\end{array}$} & \multirow{3}{*}{$\begin{array}{r}\Delta \mathrm{P}_{0}^{\mathrm{n}} \\
(\$)\end{array}$} & \multirow{3}{*}{$\begin{array}{c}\Delta \mathrm{Q}_{0}^{\mathrm{n}} \\
(\mathrm{lb})\end{array}$} & \multirow{3}{*}{$\begin{array}{r}\Delta \mathrm{P}_{0}^{\mathrm{n}} / \mathrm{P}_{0} \\
(\%)\end{array}$} & \multirow{3}{*}{$\begin{array}{r}\Delta \mathrm{Q}_{0}^{\mathrm{n}} / \mathrm{Q}_{0}^{\mathrm{n}} \\
(\%)\end{array}$} & \multirow{3}{*}{$\begin{array}{l}\mathrm{P}_{0}^{\mathrm{n}} \\
(\$)\end{array}$} & \multirow{3}{*}{$\begin{array}{l}\mathrm{Q}_{0}^{\mathrm{n}} \\
(\mathrm{lb})\end{array}$} \\
\hline & & & & & & & & & \\
\hline & 1 & 2 & 3 & & & & & & \\
\hline Average & 0 & 0 & 0 & 0 & 0 & 0 & 0 & 2.50 & 10,000 \\
\hline$\alpha$ & -2 & -8 & -5 & -0.45 & 2,576 & -18.2 & 8.6 & 2.05 & 12,576 \\
\hline$\beta$ & -12 & 12 & 5 & 0.11 & -790 & 4.4 & -2.6 & 2.61 & $9,210.0$ \\
\hline$\gamma$ & 14 & -4 & 0 & 0.34 & $-1,786$ & 13.8 & -6.0 & 2.84 & 8.214 .0 \\
\hline
\end{tabular}

Prices and quantities of products for $\alpha, \beta$ and $\gamma$ in the equilibrium are shown in Table 1 . Note that according to the definition of price-value potential in Eq. 28, its properties shown in Eq. 32 and calculated results shown in Table 1, price-value potentials for all three products in market equilibrium are equal, i.e.:

$$
\varphi_{0}^{\alpha}=\varphi_{0}^{\beta}=\cdots=\varphi_{0}^{\gamma}
$$

that completely meets the price-value potential conservation principle formulated in Eq. 34 and 38.

As seen from Table 1, the equilibrium prices for strawberries $\alpha, \beta$ and $\gamma$ reflect the correspondent differentiation in the almost perfectly competitive market. Thus we can conclude that though in the classical model of perfect competition all participants of the market must use the same price for all products, the differentiation approach described above provides constructive suggestions on price variation due to product differentiation.

\section{CONCLUSION}

A near-perfectly competitive market is similar to a classical perfectly competitive market except the former allows for small differentiations within the group of products while perfect competition implies completely homogeneous products. A near-perfectly competitive market exists in reality where buying decisions are made on market equilibrium prices against product differentiation, as opposed to simply price taking in perfect competition. Perfectly competitive markets do not exist in reality because products, even similar products, always show some differentiation. The concept of a near-perfectly competitive market is also different from monopolistic competition, where differentiation may be significant, brands play a role and buyers make their decisions based on more than just a price-differentiation basis.

Equilibrium prices and quantities for products with small differentiations in near-perfectly competitive markets were discussed and analyzed in this study. It was shown that the differences of prices and quantities of such products are proportional to differentiation.
Different equilibrium prices for a group of products in a near-perfectly competitive market make it impossible to discuss market equilibrium for the entire group of products within the framework of a classical pricequantity approach. In result, actual recommendations to market participants are basically made impossible within the model of perfect competition.

By analogy with physics, money plays the role of energy in the market, but it is well known from physics that energy in not the only parameter responsible for motion and equilibrium. Price-value potential was introduced by analogy with free energy or thermodynamic potential in physics and used for market demand and supply equilibrium analysis instead of price. The price-value potential conservation principle was formulated. The conservation principle states that all products in a market steady state or equilibrium have the same level of price-value potential.

The price-value potential was applied for the analysis of a near-perfectly competitive market. It was shown in this study that for a group of products with small differentiations in a near-perfectly competitive market, the equilibrium price-value potential is the same for all products in the group in contrast to different equilibrium prices. Thus the entire group of products can be considered the common market equilibrium. This was impossible to do in the traditional price-quantity approach. The prices for each differentiated product in the group vary according to the corresponding differentiation part of the price-value potential. The price-value potential approach is a constructive enhancement to the classic economic theory because it provides a more comprehensive view of the market of products with differentiations. Pricevalue potential can be used to analyze a market of a group of products with small differentiations in equilibrium as a whole, as well as to find the appropriate variations of equilibrium prices and quantities in this market. The classical approach based on price and quantity for demand and supply fails in such analysis while the price-value and quantities approach leads to constructive results.

For example, according to the classical model of perfect competition, all products on the market are sold at the same price. Such a model is an abstraction that 
has no practical application because in the real world products always have some differentiations and for this reason are sold at different prices. The new approach of price-value potential easily handles such a situation.

The price-value potential and its conservation principle lay out the foundations for further enhancement of economic theory. In future studys, the price-value approach will be applied to the analysis of different markets. This approach will also be applied to the analysis of intra-market and cross-market equilibrium, steady state and dynamics.

\section{ACKNOWLEDGEMENT}

The author is very grateful to Nicole Marsh for her valuable help in the preparation of this study for publication.

\section{REFERENCES}

Block, W., W. Barnett and S. Wood, 2002. Austrian economics, neoclassical economics, marketing and finance. Quarterly J. Austrian Econ., 5: 51-66. DOI: $10.1007 / \mathrm{s} 12113-002-1012-9$

Boldrin, M. and D.K. Levine, 2008. Perfectly competitive innovation. J. Monetary Econ., 55: 435-453. DOI: 10.1016/j.jmoneco.2008.01.008

Bradley, M.E., 2010. Adam smith's system of natural liberty: Competition, contestability and market process. J. History Econ. Thought, 32: 237-262. DOI: $10.1017 / \mathrm{S} 1053837210000131$

Briglauer, W. and K. Reichinger, 2008. Chances of contestability in communications. Intereconomics, 43: 51-64. DOI: 10.1007/s10272-008-0241-3

Dixit, A.K. and J.E. Stiglitz, 1977. Monopolistic competition and optimum product diversity. Am. Econ. Rev., 67: 297-308.

Dixit, A.K. and J.E. Stiglitz, 1993. Monopolistic competition and optimum product diversity: Reply. Am. Econ. Rev., 83: 302-302.

Fradera, I., 1986. Perfect competition with product differentiation. Int. Econ. Rev., 27: 529-238.

Hart, O.D., 1979. Monopolistic competition in large economy with differentiated products. Rev. Econ. Stud., 46: 1-30. DOI: 10.2307/2297169

Hart, O.D., 1980. Perfect competition and optimal product differentiation. J. Econ. Theory, 22: 279312. DOI: 10.1016/0022-0531(80)90044-7

Landau, L.D. and E.M. Lifshitz, 1980. Statistical Physics. Part 1 Course of Theoretical Physics, Butterworth-Heinemann.
Mas-Colell, 1975. A model of equilibrium with differentiated commodities. J. Math. Econ., 2: 263-295.

McAfee, R.P. and V. Velde, 2008. Dynamic pricing with constant demand elasticity. Product. Operat. Manag., 17: 432-438. DOI: 10.3401/poms. 1080.0041

Mishra, S.S. and P.P. Mishra, 2008. Price determination for an EOQ model for deteriorating items under perfect competition. Comp. Math. Appl., 56: 10821101. DOI: 10.1016/j.camwa.2008.01.034

Novshek, W. and H. Sonnenschein, 1980. Small efficient scale as a foundation for Walrasian equilibrium. J. Econ. Theory, 22: 243-255.

Novshek, W. and H. Sonnenschein, 2012. Cournot and Walras equilibrium. J. Econ. Theory, 19: 223-266.

Novshek, W., 1980. Cournot equilibrium with free entry. Rev. Econ. Stud., 47: 473-486.

Paul, A.S. and W.D. Nordhaus, 2009. Economics. 18th Edn., McGraw-Hill, New Delhi, ISBN-10: 007059855X, pp: 776.

Petersen, H.C. and W.C. Lewis, 1999. Managerial Economics. 4rth Edn., Prentice Hall, ISBN-10: 0139762833, pp: 672.

Pindyck, R. and D. Rubinfeld, 2009. Microeconomics. 7th Edn., Pearson Studium, Munchen Boston, ISBN-10: 9783827372826, pp: 959.

Puu, T., 2008. On the stability of cournot equilibrium when the number of competitors increases. J. Econ. Behav. Organ., 66: 445-456. DOI: 10.1016/j.jebo.2006.06.010

Reiss, H., 1996. Methods of Thermodynamics. 1st Edn., Dover Publications, Mineola, New York, ISBN-10: 0486694453 pp: 217.

Shneyerov, A. and A.C.L. Wong, 2010. The rate of convergence to perfect competition of matching and bargaining mechanisms. J. Econ. Theory, 145: 1164-1187. DOI: 10.1016/j.jet.2010.02.009

Stigler, G.J., 1995. Essays in the History of Economics. 1st Edn., University of Chicago Press, Chicago: London, pp: 391.

Sun, Y. and N.C. Yannelis, 2007. Perfect competition in asymmetric information economies: compatibility of efficiency and incentives. J. Econ. Theory, 134: 175-194. DOI: 10.1016/j.jet.2006.03.001

Thampapillai, D.J., 2010. Perfect competition and sustainability: A brief note. Int. J. Soc. Econ., 37: 384-390. DOI: 10.1108/03068291011038963 